\title{
ATP-binding cassette transporter A1 gene polymorphisms and serum lipid levels in young Greek nurses
}

\author{
Vana Kolovou', Genovefa Kolovou², Apostolia Marvaki', Agathi Karakosta ${ }^{3}$, Georgios Vasilopoulos ${ }^{4}$, \\ Antonia Kalogiani ${ }^{4}$, Dimitrios Degiannis ${ }^{1}$, Christina Marvaki ${ }^{4}$ and Constantinos A Demopoulos ${ }^{5}$
}

\begin{abstract}
Objective: The ATP-binding cassette transporter A1 (ABCA1) is essential protein involved in lipid metabolism. The present study was undertaken to detect the possible association of polymorphisms in the ABCA1 gene [rs2230806 (R219K) and rs2230808 (R1587K)] and lipid profile in Greek young nurses.

Methods: The study population consisted of 308 unrelated nurses who were genotyped and the ABCA1 polymorphisms were detected. Additionally, lipid profile [total cholesterol (TC), triglycerides (TGs), high density lipoprotein cholesterol (HDL-C), low density lipoprotein cholesterol (LDL-C) and apolipoprotein (apo) A] was evaluated.
\end{abstract}

Results: There was no difference in the genotypic and allelic frequencies of the R219K polymorphism according to lipid profile. The R1587K genotypes differed significantly according to TC, LDL-C and TGs concentration ( $p=0.023$, $p=0.014$ and $p=0.047$, respectively). Particularly, significant difference in TC, LDL-C and TGs concentration was detected between RK and RR genotypes ( $p=0.006, p=0.004, p=0.014$, respectively). Women with RK genotype compared to RR genotype had higher concentration of TGs $(134.25 \mathrm{mg} / \mathrm{dl}$ vs $108.89 \mathrm{mg} / \mathrm{dl}, \mathrm{p}=0.014$, respectively), total cholesterol $(207.41 \mathrm{mg} / \mathrm{dl}$ vs $187.69 \mathrm{mg} / \mathrm{dl}, \mathrm{p}=0.006$, respectively), and LDL-C (110.6 mg/dl vs $96.9 \mathrm{mg} / \mathrm{dl}, \mathrm{p}=$ 0.004 , respectively).

Conclusions: These findings suggest that the R1587K polymorphism of ABCA1 gene was associated with lipid profile of Greek nurses. Women with RK genotype had higher TGs, total and LDL-C concentration compared to RR genotype. These observations may be significant in assessing the risk of CAD since a $1 \%$ change in LDL-C is associated with a 1\% change of cardiovascular events. Also, TGs concentration were documented to play a significant role in women. However, this needs to be confirmed by larger studies.

\section{Introduction}

The ATP-binding cassette transporter A1 (ABCA1) acts as a vehicle for cellular cholesterol which after crossing cell membrane bounds to acceptor molecule such as apolipoprotein (apo) A [1-3]. Thus, ABCA1 influences the initial steps in high density lipoprotein (HDL) formation and in reverse cholesterol transport. The $\mathrm{ABCA} 1$ protein belongs to $\mathrm{ABC}$ proteins family, which are ingredients of biological membranes and use ATP to transfer various particles such as lipids [1]. The ABCA1

\footnotetext{
* Correspondence: genovefa@kolovou.com

${ }^{2}$ 1st Cardiology Department, Onassis Cardiac Surgery Center Athens, Greece Full list of author information is available at the end of the article
}

protein gene is located in the chromosome 9 in the area 9q31.1. This gene encodes a protein which is expressed in many tissues such as liver, macrophages, intestines, lungs etc. Several ABCA1 gene polymorphisms were identified, including rs2230806 (R219K) and rs2230808 (R1587K), which are mainly associated with the HDL cholesterol (HDL-C) concentration. The R219K results in a single amino acid change in codon 219 from arginine to lysine. The $\mathrm{K}$ allele of the $\mathrm{R} 219 \mathrm{~K}$ polymorphism has been related to low coronary artery disease (CAD) risk [4] and to lower triglycerides (TGs) concentration [5]. As far as concern the levels of HDL-C the reports are still confusing $[4,6]$. The R1587K which is located in
Ciomed Central

(c) 2011 Kolovou et al; licensee BioMed Central Ltd. This is an Open Access article distributed under the terms of the Creative Commons Attribution License (http://creativecommons.org/licenses/by/2.0), which permits unrestricted use, distribution, and reproduction in any medium, provided the original work is properly cited. 
the extracellular loop of the ABCA1 protein, results in a single amino acid change in codon 1587 . This polymorphism has been consistently associated with low HDL-C concentration $[7,8]$.

This study was undergone to evaluate the influence of these two ABCA1 gene polymorphisms on lipid profile [total cholesterol, TGs, HDL-C and low density lipoprotein cholesterol (LDL-C)] in young nurses. We also tested if there are any differences in frequency of ABCA1 gene polymorphisms between individuals with low and high HDL-C concentration.

\section{Materials and methods}

\section{Subjects}

The genotyping of 308 Greek female students aged 22.5 $( \pm 2.3)$ years who were attended to the University of Nursing of Technological and Educational Institution was performed. All students had no personal history of $\mathrm{CAD}$ and were not taking any drugs. Also, exclusion criteria were diabetes mellitus, thyroid and liver disease, high alcohol consumption, professional athleticism and any chronic disease.

All women were attended to the University every day and were staying for 8-10 hours. Women were eating at the school canteen which served typical Mediterranean food. Only one (evening) meal daily was most likely to be different in each student.

Additionally, subject were divided to those with high (HDL-C $>70 \mathrm{mg} / \mathrm{dl}$ ) and low (HDL-C $<40 \mathrm{mg} / \mathrm{dl}$ ) HDL$\mathrm{C}$ concentration.

The University of Nursing of Technological and Educational Institution ethics committee approved the protocol of this study. All subjects signed an informed consent form.

\section{Blood Chemistry}

Plasma total cholesterol, TGs, HDL-C and apo A1 were measured using enzymatic colorimetric methods on Roche Integra Biochemical analyzer with commercially available kits (Roche). The serum LDL-C concentration was calculated using the Friedewald formula only in patients with TGs concentration $<400 \mathrm{mg} / \mathrm{dl}$.

\section{DNA analysis and determination of blood lipids}

The ABCA1 gene polymorphisms (R219K and R1587K) were detected using polymerase chain reaction (PCR) and restricted fragment length polymorphism analysis (RFLP's). The PCR was performed using Taq polymerase KAPATaq. For R219K polymorphism the oligonucleotide primers which were used are AAAGACTTCAAGGACCCAGCTT and CCTCACATTCCGAAAGCATTA [9]. PCR was subjected to $95^{\circ} \mathrm{C}$ for $5 \mathrm{~min}$, thirty cycles of $95^{\circ} \mathrm{C}$ for $30 \mathrm{~s}, 55^{\circ} \mathrm{C}$ for $30 \mathrm{~s}$ and $72^{\circ} \mathrm{C}$ for $30 \mathrm{~s}$ and final extension to $72^{\circ} \mathrm{C}$ for $7 \mathrm{~min}$, producing a fragment of $309 \mathrm{bp}$. This fragment was subsequently cleaved by EcoNI, creating fragments for $\mathrm{R}$ allele $309 \mathrm{bp}$ and for $\mathrm{K}$ allele $184 \mathrm{bp}$ and $125 \mathrm{bp}$, which were subjected to electrophoresis on an agarose gel $4 \%$ and visualized with ethidium bromide.

For R1587K polymorphism the oligonucleotide primers which were used are AAGATTTATGACAGGACTGGACACGA and TGAATGCCCCTGCCAACTTTAC [8]. PCR was subjected to $95^{\circ} \mathrm{C}$ for $5 \mathrm{~min}$, thirty cycles of $95^{\circ}$ $\mathrm{C}$ for $30 \mathrm{~s}, 60^{\circ} \mathrm{C}$ for $30 \mathrm{~s}$ and $72^{\circ} \mathrm{C}$ for $30 \mathrm{~s}$ and final extension to $72^{\circ} \mathrm{C}$ for $7 \mathrm{~min}$, producing a fragment of $139 \mathrm{bp}$. This fragment was subsequently cleaved by BssSI, creating fragments for $\mathrm{R}$ allele $117 \mathrm{bp}$ and $22 \mathrm{bp}$ and for $\mathrm{K}$ allele $139 \mathrm{bp}$, which were subjected to electrophoresis on an agarose gel $4 \%$ and visualized with ethidium bromide (Figure 1, Figure 2).

\section{Statistical analysis}

The results are given as mean \pm standard deviation (SD) or as median and interquartile range (IQR) according to normality of continuous variables. All qualitative variables are presented as absolute or relative frequencies. All biochemical variables were assessed for normality of distribution employing the Shapiro-Wilk test and non parametric statistical tests were used if appropriate. However, non parametric variables were initially normalized; TGLs by the $\log 10$ transformation - apoA1 and $\mathrm{TC}$ by square root transformation and parametric criteria were employed, all providing the same results as

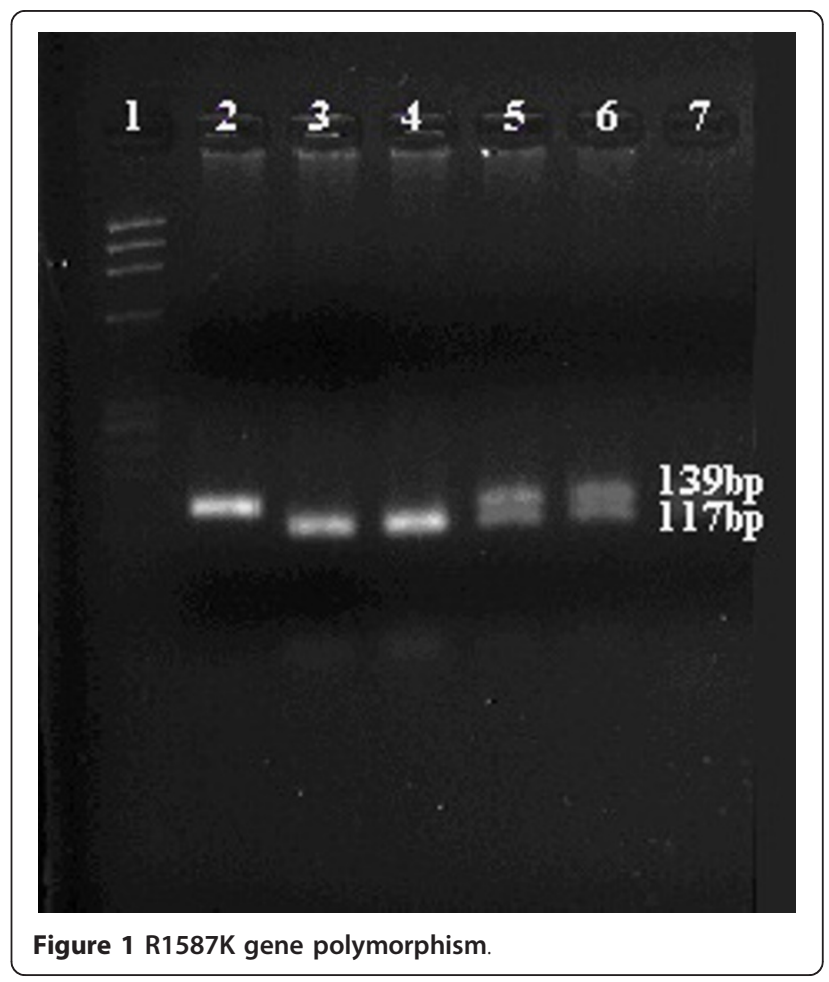




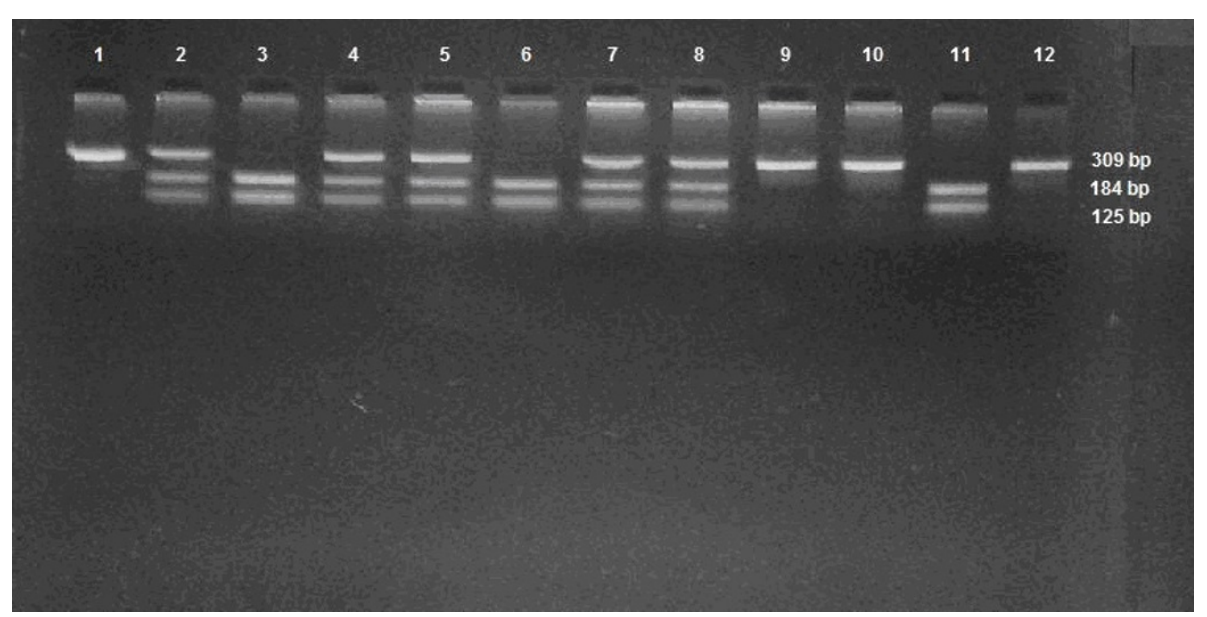

Figure 2 R219K gene polymorphism.

non parametric tests. However, TGL variable was extremely skewed and we decided to use the median [IQR] presentation and keep the result of the non parametric test that was employed.

Differences in lipid levels for the various genotypes were evaluated with one - way analysis of variance (ANOVA) or its non-parametric analogue Kruskal Wallis H statistic. The Pearson's chi-square test was employed for the categorical variables.

All tests were two-tailed and statistical significance was established at $5 \%(\mathrm{p}<0.05)$. Data were analyzed using Stata ${ }^{\mathrm{TM}}$ (Version 10.1 MP, Stata Corporation, College Station, TX 77845, USA).

\section{Results}

\section{Clinical and laboratory parameters}

Demographic data, clinical characteristics and lipid profile of the study cohort are shown in Table 1 . R and $\mathrm{K}$ allele frequencies appear to have equal distributions in both ABCA1 polymorphisms ( $p>0.05$ ) (Table 2). The frequencies of $\mathrm{R} 219 \mathrm{~K}$ genotypes were $50.97 \%$ for $\mathrm{RR}$,

Table 1 Characteristics of the study population

\begin{tabular}{llll}
\hline Demographic data & & \multicolumn{2}{l}{ Lipid profile(in $\mathbf{m g} /$ dl) } \\
\hline Number of subjects & 308 & Total Cholesterol & $196.6(59.7)$ \\
Age $(\mathrm{ys})$ & $22.5(2.3)$ & TGs & $87[60.5-149]$ \\
BMl $\left(\mathrm{Kg} / \mathrm{m}^{2}\right)$ & $21.5[19.8-24.2]$ & $\mathrm{HDL}-\mathrm{C}$ & $69.2(25.9)$ \\
Waist $(\mathrm{cm})$ & $87.0(12.5)$ & LDL-C & $103.5(38.8)$ \\
& & Apo A & $152.8(53.5)$ \\
\hline
\end{tabular}

\section{Clinical characteristics}

Smoking (yes/no) 110/176 (38.5\%/61.5\%)

HDL-C: high density lipoprotein cholesterol, LDL-C: low density lipoprotein cholesterol, ApoA1: Apolipoprotein A1, TGs: triglycerides. Data are expressed as mean \pm standard deviation (SD) or as median and interquartile range (IQR) according to normality of continuous variables. Qualitative variables are presented as absolute and relative frequencies.
40.91\% for RK and $8.12 \%$ for KK, whereas the frequencies of R1587K genotypes were $47.08 \%$ for RR, $41.56 \%$ for RK and $11.36 \%$ for KK. Both frequencies were found in Hardy-Weinberg equilibrium.

\section{R219K and R1587K polymorphisms}

The distribution of $\mathrm{R} 219 \mathrm{~K}$ and $\mathrm{R} 1587 \mathrm{~K}$ polymorphisms was investigated according to Low HDL-C $(n=46)$ and High HDL-C concentration $(n=104)$. No statistical difference was observed in both polymorphisms when compared to Low vs High HDL-C concentration ( $\mathrm{p}=0.44$ and $\mathrm{p}=0.48$, respectively). Moreover, no difference in the distribution of the R219K genotypes was detected according to lipid profile (Table 2). Also, no differences in the distribution of $\mathrm{K}$ and $\mathrm{R}$ carriers of $\mathrm{R} 219 \mathrm{~K}$ polymorphism was detected according to lipid profile $(\mathrm{p}=0.87)$.

The R1587K genotypes differed significantly according to total cholesterol, LDL-C and TGs concentration ( $\mathrm{p}=$ $0.023, p=0.014$ and $p=0.047$, respectively) (Table 3). Significant difference in LDL-C concentration was detected between RK and RR genotypes of the same polymorphism (110.6 mg/dl vs $96.9 \mathrm{mg} / \mathrm{dl}$, respectively, $\mathrm{p}=0.004$ ), Figure 3. However, the LDL-C concentration did not differ between women with the KK and RK genotype of the R1587K polymorphism (104.52 mg/dl vs $110.64 \mathrm{mg} / \mathrm{dl}, \mathrm{p}$ $=0.4$ ). Total cholesterol levels was higher in women with the RK compared to women with the RR genotype of the R1587K polymorphism (207.41 mg/dl vs $187.69 \mathrm{mg} / \mathrm{dl}, \mathrm{p}$

Table $2 \mathrm{R}$ and $\mathrm{K}$ allele frequencies according to $\mathrm{R} 219 \mathrm{~K}$ and $R 1587 \mathrm{~K}$ polymorphisms

\begin{tabular}{lccc}
\hline ABCA1 & R allele frequency & K allele frequency & p value* \\
\hline R219K & 0.72 & 0.28 & 0.11 \\
R1587K & 0.68 & 0.32 & \\
\hline
\end{tabular}

Fisher's exact test 
Table 3 Blood lipid levels according to ABCA1 R1587K polymorphism in all genotypes

\begin{tabular}{|c|c|c|c|c|}
\hline Lipid Profile (in mg/dl) & Genotype & Mean & SD & $\mathrm{P}^{*}$ \\
\hline & $\mathrm{RR}$ & 187.69 & 59.19 & \\
\hline \multirow[t]{3}{*}{ Total cholesterol } & RK & 207.41 & 59.55 & 0.023 \\
\hline & KK & 193.65 & 57.49 & \\
\hline & $\mathrm{RR}$ & 68.94 & 26.35 & \\
\hline \multirow[t]{3}{*}{$H D L-C$} & RK & 69.89 & 25.33 & 0.88 \\
\hline & KK & 67.48 & 26.57 & \\
\hline & $\mathrm{RR}$ & 96.97 & 38.48 & \\
\hline \multirow[t]{3}{*}{$L D L-C$} & RK & 110.64 & 37.26 & 0.014 \\
\hline & KK & 104.52 & 41.51 & \\
\hline & $\mathrm{RR}$ & 147.8 & 53.23 & \\
\hline \multirow[t]{4}{*}{ ApoA1 (mg/dl) } & RK & 158.46 & 54.33 & 0.26 \\
\hline & KK & 152.54 & 50.65 & \\
\hline & Genotype & Median & IQR & $\mathbf{P}^{+}$ \\
\hline & $\mathrm{RR}$ & 83 & {$[56-123]$} & \\
\hline \multirow[t]{2}{*}{ TGs } & RK & 98 & {$[63.5-180]$} & 0.047 \\
\hline & KK & 79 & {$[61-134]$} & \\
\hline
\end{tabular}

HDL-C: high density lipoprotein cholesterol, LDL-C: low density lipoprotein cholesterol, ApoA1: Apolipoprotein A1, TGs: triglycerides. *P values among genotypes from Anova test performance - ${ }^{\dagger} \mathrm{P}$ values among genotypes from Kruskal Wallis test performance.

$=0.006)$, whereas total cholesterol levels did not differ between women with RK and KK genotypes $(207.41 \mathrm{mg} / \mathrm{dl}$ vs $193.66 \mathrm{mg} / \mathrm{dl}, \mathrm{p}=0.22$ ). Finally, a significant difference was observed in the levels of TGs according to the R1587K polymorphism, with the RK genotype women having higher TGs concentration in comparison to the RR genotype (134.25 mg/dl vs $108.89 \mathrm{mg} / \mathrm{dl}, \mathrm{p}=0.014)$. However, TGs levels did not seem to differ between RK and KK genotypes of the same polymorphism $(134.25 \mathrm{mg} / \mathrm{dl}$ vs $108.06 \mathrm{mg} / \mathrm{dl}, \mathrm{p}=0.11$ ). Also, no differences in the distribution of $\mathrm{K}$ and $\mathrm{R}$ carriers of $\mathrm{R} 1587 \mathrm{~K}$ polymorphism was detected according to lipid profile $(\mathrm{p}=0.5)$.

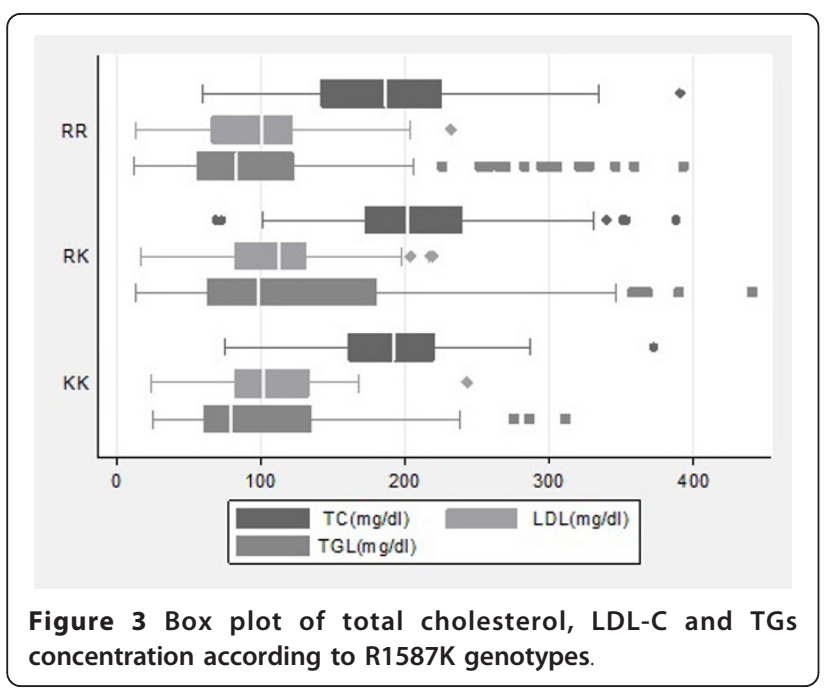

\section{Discussion}

We examined the probable impact of the ABCA1 polymorphisms as a genetic influence on lipid profile in Greek young nurses.

\section{R219K gene polymorphism}

The frequency of $\mathrm{R}$ allele of $\mathrm{R} 219 \mathrm{~K}$ polymorphism in our study was $72 \%$ similar to Pasdar et al [10] who reported $73.2 \%$ in controls $(68 \%$ in patients with ischemic stroke) and Porchay et al [11] [D.E.S.I.R participants (Data from an Epidemiological Study on the Insulin Resistance)] who reported $71.7 \%$. Conversely, Clee et al [5] reported frequency of $46 \%$ in Dutch men with proven CAD who participated in the Regression Growth Evaluation Statin Study.

Concerning lipid profile, the possibly influence of the R219K polymorphism is still evaluated. For example, Hodoğlugil et al in Turks individuals with low HDL-C concentration found the association of R219K polymorphism with HDL-C concentration [12]. FrikkeSchmidt et al in Danish population did not found any association between $\mathrm{R} 219 \mathrm{~K}$ polymorphism and individuals with Low or High HDL-C concentration [7]. On the other hand, Kakko et al in Finnish women [13] found the association of $219 \mathrm{~K}$ allele with higher HDL-C concentration. Opposite, Clee et al [5] reported no differences according to HDL-C concentration between $\mathrm{K}$ or $\mathrm{R}$ allele, although carriers of $\mathrm{K}$ allele had significant lower TGs concentration in relation to carriers of $\mathrm{R}$ allele [5]. Furthermore, younger homozygotes of $\mathrm{K}$ allele had higher cholesterol efflux and HDL-C concentration compared to homozygotes of $\mathrm{R}$ allele. Sandhofer et al [14] studied male population and did not find any association of R219K polymorphism and lipid profile. Also, Cenarro et al [15] evaluated the R219K polymorphism in patients with familial hypercholesterolemia with and without premature $\mathrm{CAD}$ and reported that $\mathrm{K}$ allele was more frequent in subjects without premature CAD compared to individuals with premature CAD [15]. Li et al [16] investigated the relation of $\mathrm{R} 219 \mathrm{~K}$ polymorphism with the manifestation of CAD in Chinese patients and did not report any significant correlation. However, the TGs concentration were significant higher and HDL-C concentration significant lower in patients with RR genotype than those with KK genotype. Similarly, DelgadoLista J et al [17] did not find association of R219K polymorphism and lipid profile.

According to our results from the young Greek female nurses (living and working in the similar conditions) we did not find any association with HDL-C concentration or other lipid parameters. Also, no association between R219K polymorphism and Low or High HDL-C subgroups was found although small number involved in these groups may be a limitation. 


\section{R1587K gene polymorphism}

The frequency of $\mathrm{R}$ allele of $\mathrm{R} 1587 \mathrm{~K}$ polymorphism in our study was $68 \%$. Pasdar et al [10] reported $75.9 \%$ and Frikke-Schmidt reported 76\% [18].

Also, Frikke-Schmidt et al [7] found that this polymorphism is overexpresed in individuals (men and women) with low HDL-C concentration. Furthermore, there was a gradual decrease in HDL-C levels about $0.07 \mathrm{mmol} / \mathrm{l}(2.7 \mathrm{mg} / \mathrm{dl})$ for RK genotype and 0.11 $\mathrm{mmol} / \mathrm{l}(4.2 \mathrm{mg} / \mathrm{dl})$ for the RR genotype. Tregouet et al [19] stated that R1587K has impact on the apo A1 concentration. Wang et al [20] did not found any relation of R1587K with lipids levels in patients with type 2 diabetes mellitus who were treated with rozigliatoze. The study of Clee et al [5] in Danish population has shown that carriers of $\mathrm{K}$ allele had lower HDL-C concentration in comparison with the KK genotype. In a multi-analysis including age, BMI, smoking and TGs as independent variables, the R1587K polymorphism remained significant factor for the prediction of HDL-C concentration. Pasdar et al [10] found the association of R1587K polymorphism and apo A concentration and this was not related to CAD. Cohen et al [21] supported that rare alleles with major phenotypic effects contribute significantly to low HDL-C levels in the general population. However, Tupitsina et al [9] observed that in patients with CAD the R1587K polymorphism did not affect lipids levels. Slatter et al [22] investigated the prevalence of mutations and common SNPs in ABCA1 in 154 low HDL-C individuals and 102 high HDL-C individuals. The R1587K SNP was over represented in low HDL-C individuals. Ksiazek et al in a small study of 50 individuals reported a trend $(\mathrm{p}=0.07)$ in terms of association between TGs concentration and R1587K genotype [23]. In our study no association between R1587K polymorphism and HDL-C levels was found. Also, no association between R1587K polymorphism and Low or High HDL-C subgroups was found. However, individuals with RK genotype had significantly higher TGs, total cholesterol and LDL-C concentration compared to RR genotype.

Reduced circulating HDL-C can be caused by either genetic and/or environmental factors (sedentary lifestyle, diabetes mellitus, smoking, obesity or a diet enriched in carbohydrates). The potential mechanisms of interaction between genetic variations and phenotypes contribution are not fully understood. This happens because each study involved different studying population and the environmental interactions could not be ruled out. Thus, in our study the environmental influence was partially diminished. The advantage of our study was that the study cohort was almost homogenous, since the nurses most of the time were following the same day to day program and were eating in the same school canteen. Thus the influence of diet or physical activities were unlikely, which may partially explain the lack of association of $\mathrm{R} 219 \mathrm{~K}$ or $\mathrm{R} 1587 \mathrm{~K}$ polymorphisms and HDL-C concentration. However, the influence of smoking cannot be ruled out since $38.5 \%$ of students were smokers.

It is well known from clinical trials, that $1 \%$ change in LDL-C is associated with a $1 \%$ change of cardiovascular events, which means that individuals born with favorable genotype (in this case RR genotype of R1587K) have already some advantage compare to less favorable genotypes, since they have lower LDL-C. At that time, this was only a clinical observation. Hopefully in near future we will be able to identify high risk patients according to genetic testing, which the assessment in these days has same cost, time implications and replication problems in independent studies, which are disadvantages in routine clinical practice. Nevertheless, these limitations may become less relevant as technology develops.

In summary, the R $1587 \mathrm{~K}$ polymorphism of ABCA1 gene was associated with altered lipid levels in Greek young nurses. Women with RK genotype had higher TGs, total and LDL-C concentration compared to RR genotype. These observations may be significant in assessing the risk of CAD since a $1 \%$ change in LDL-C is associated with a $1 \%$ change of cardiovascular events and TGs concentration were documented to play a significant role in women.

\section{Author details \\ ${ }^{1}$ Molecular Immunology Laboratory, Onassis Cardiac Surgery Center Athens, Greece. ${ }^{2} 1$ st Cardiology Department, Onassis Cardiac Surgery Center Athens, Greece. ${ }^{3}$ Thriassio General Hospital, Magoula, Attica, Greece. ${ }^{4}$ Department of Nursing, A' Technological Educational Institute of Athens, Greece. \\ ${ }^{5}$ Department of Chemistry, National and Kapodistrian University of Athens, Greece.}

\section{Authors' contributions}

VK participated in the development of hypothesis, drafting of the manuscript and carried out the genetic analysis, GK conceived the study and participated in the development of the hypothesis, the study design and drafting of the manuscript, AM participated in the molecular genetic studies, AK performed the statistical analysis and drafting of the manuscript, GV and AK collected the blood samples, DD participated in revising the manuscript critically for important intellectual content, CM and CD participated in the study design and its coordination. All authors read and approved the final manuscript.

\section{Competing interests}

The authors declare that they have no competing interests.

Received: 4 February 2011 Accepted: 13 April 2011

Published: 13 April 2011

\section{References}

1. Kolovou GD, Mikhailidis DP, Anagnostopoulou KK, Daskalopoulou SS, Cokkinos DV: Tangier disease four decades of research: a reflection of the importance of HDL. Curr Med Chem 2006, 13:771-82.

2. von Eckardstein A, Nofer JR, Assmann G: High density lipoproteins and arteriosclerosis. Role of cholesterol efflux and reverse cholesterol transport. Arterioscler Thromb Vasc Biol 2001, 21:13-27. 
3. Dean M, Hamon Y, Chimini G: The human ATP-binding cassette (ABC) transporter superfamily. J Lipid Res 2001, 42:1007-1017.

4. Benton JL, Ding J, Tsai MY, et al: Associations between two common polymorphisms in the ABCA1 gene and subclinical atherosclerosis: Multi-Ethnic Study of Atherosclerosis (MESA). Atherosclerosis 2007, 193:352-60.

5. Clee SM, Zwinderman $\mathrm{AH}$, Engert JC, et al: Common genetic variation in $A B C A 1$ is associated with altered lipoprotein levels and a modified risk for coronary artery disease. Circulation 2001, 103:1198-205.

6. Takagi S, Iwai N, Miyazaki S, Nonogi H, Goto Y: Relationship between $A B C A 1$ genetic variation and HDL cholesterol level in subjects with ischemic heart diseases in Japanese. Thromb Haemost 2002, 88:369-70.

7. Frikke-Schmidt R, Nordestgaard BG, Jensen GB, Tybjaerg-Hansen A: Genetic variation in $A B C$ transporter $A 1$ contributes to $\mathrm{HDL}$-cholesterol in the general population. J Clin Invest 2004, 114:1343-53.

8. Saleheen D, Khanum S, Haider SR, et al: A novel haplotype in ABCA1 gene effects plasma HDL-C concentration. Int J Cardiol 2007, 31:7-13, 115.

9. Tupitsina TV, Slominsky PA, Yefereva YM, Perova NI, Aronov DM, Limborska SA: Linkage analysis by a transmission/Disequilibrium of Russian sibling pairs with coronary artery disease. BJMG 2007, 10:43-54.

10. Pasdar A, Yadegarfar G, Cumming A, Whalley L, St Clair D, MacLeod MJ: The effect of $A B C A 1$ gene polymorphisms on ishaemic stroke and relationship with lipid profile. BMC Med Genet 2007, 8:30.

11. Porchay I, Péan F, Bellili N, et al: ABCA1 single nucleotide polymorphisms on high-density lipoprotein-cholesterol and overweight: the D.E.S.I.R. study. Obesity (Silver Spring) 2006, 14:1874-9.

12. Hodoğlugil U, Williamson DW, Huang Y, Mahley RW: Common polymorphisms of ATP binding cassette transporter A1, including a functional promoter polymorphism, associated with plasma high density lipoprotein cholesterol levels in Turks. Atherosclerosis 2005, 183:199-212.

13. Kakko S, Kelloniemi J, von Rohr P, et al: ATP-binding cassette transorter A1 locus is not a major determinant of HDL-C levels in a population at high risk for coronary heart disease. Atherosclerosis 2003, 166:285-90.

14. Sandhofer A, Iglseder B, Kaser S, Morè E, Paulweber B, Patsch JR: The influence of two variants in the adenosine triphosphate-binding cassette transporter 1 gene on plasma lipids and carotid atherosclerosis. Metabolism 2008, 57:1398-404.

15. Cenarro A, Artieda M, Castillo $S$, et al: $A$ common variant in the ABCA1 gene is associated with a lower risk for premature coronary heart disease in familial hypercholesterolaemia. J Med Genet 2003, 40:163-8.

16. Li J, Wang LF, Li ZQ, Pan W: Effect of R219K polymorphism of the ABCA1 gene on the lipid-lowering effect of pravastatin in Chinese patients with coronary heart disease. Clin Exp Pharmacol Physiol 2009, 36:567-70.

17. Delgado-Lista J, Perez-Martinez P, Perez-Jimenez F, et al: ABCA1 gene variants regulate postprandial lipid metabolism in healthy men. Arterioscler Thromb Vasc Biol 2010, 30:1051-7.

18. Frikke-Schmidt R, Nordestgaard BG, Jensen GB, Steffensen $R$, TybjaergHansen A: Genetic variation in ABCA1 predicts ischemic heart disease in the general population. Arterioscler Thromb Vasc Biol 2008, 28:180-6.

19. Tregouet DA, Ricard S, Nicaud V, et al: In-depth haplotype analysis of ABCA1 gene polymorphisms in relation to plasma ApoA1 levels and myocardial infarction. Arterioscler Thromb Vasc Biol 2004, 24:775-81.

20. Wang J, Bao YQ, Hu C, et al: Effects of $A B C A 1$ variants on rosiglitazone monotherapy in newly diagnosed type 2 diabetes patients. Acta Pharmacol Sin 2008, 29:252-8.

21. Cohen JC, Kiss RS, Pertsemlidis A, Marcel YL, McPherson R, Hobbs HH: Multiple rare alleles contribute to low plasma levels of HDL cholesterol. Science 2004, 305:869-72.

22. Slatter TL, Jones GT, Williams MJ, van Rij AM, McCormick SP: Novel rare mutations and promoter haplotypes in ABCA1 contribute to low-HDL-C levels. Clin Genet 2008, 73:179-84.

23. Ksiazek J, Ciechanowicz A, Wierzbicka A, Syczewska M, Grenda R: Is dyslipidemia sustained during remission of nephrotic syndrome genetically determined? Evaluation of genetic polymorphisms of proteins involved in lipoprotein metabolism in children and adolescents with nephrotic syndrome. Pol Arch Med Wewn 2009, 119:11-6.

doi:10.1186/1476-511X-10-56

Cite this article as: Kolovou et al:: ATP-binding cassette transporter A1 gene polymorphisms and serum lipid levels in young Greek nurses. Lipids in Health and Disease 2011 10:56.

\section{Submit your next manuscript to BioMed Central and take full advantage of:}

- Convenient online submission

- Thorough peer review

- No space constraints or color figure charges

- Immediate publication on acceptance

- Inclusion in PubMed, CAS, Scopus and Google Scholar

- Research which is freely available for redistribution 